\title{
O léxico da série Law and Order: uma análise inicial baseada em corpus paralelo
}

\author{
The lexicon of Law and Order series: \\ initial analysis based on parallel corpus
}

\author{
Carla Regina R. O. Murad*
}

Resumo: O objetivo este trabalho foi examinar legendas do seriado Law and Order e suas spinoffs, com o intuito de explorar seu potencial terminológico e terminográfico. A principal hipótese é a de que a autenticidade da linguagem usada pelos personagens da série pode constituir um corpus rico tanto em especificidades jurídicas quanto em linguajar policial. Os pressupostos teóricos adotados foram a noção de legendas como corpora de ficção para extração de terminologia (FROMM 2011), a existência de termos emprestados de áreas de especialidade que conferem maior realidade às séries de ficção (FROMm 2011) e a elaboração de vocabulário de especialidade via Linguística de Corpus (FROMM 2007). Um corpus paralelo contendo legendas de 396 episódios em inglês americano e suas respectivas traduções para o português brasileiro foi estudado por meio do programa de análise lexical Wordsmith Tools 5.0 (ScoTT 2010). 0 estudo possibilitou a identificação da linguagem de especialidade jurídico-policial, a emergência do campo semântico Crimes e a verificação de equivalências.

Palavras-chave: Linguística de Corpus; Terminologia; Vocabulário específico; Tradução; Formação de Tradutores.

Abstract: The aim of this study was to examine subtitles of Law and Order series and its spinoffs, in order to explore its terminological and terminographic potential. The main hypothesis is that the authenticity of the language used by the characters in the series can be a rich corpus containing both legal specificities and police speech. The theoretical assumptions adopted were the notion of subtitles as fiction corpora for terminology extraction (FROMM 2011), the existence of borrowed terms of specialty areas which give greater reality to fiction series (FROMM 2011) and the elaboration of a vocabulary of specific words via Corpus Linguistics (FROMM 2007). A parallel corpus containing 396 episodes of subtitles in American English and their translations into

\footnotetext{
* Carla Regina R. O. Murad - Universidade Federal do Triângulo Mineiro. E-mail: carlamurad@gmail.com
} 
MURAD, C. R. R. O - O léxico da série Law and Order: uma análise inicial baseada em corpus paralelo

Brazilian Portuguese was studied by using the lexical analysis program Wordsmith Tools 5.0 (SCOTT 2010). The study enabled the identification of the legal and police specialty language, the emergence of the semantic field Crimes and the verification of equivalence.

Keywords: Corpus Linguistic, Terminology, Specific vocabulary, Translation, Translators' Education.

\section{Introdução}

Este artigo é um recorte do nosso Projeto de Área Complementar de Doutorado em Estudos Linguísticos ${ }^{1}$ e se insere em um projeto mais amplo intitulado Terminologia e Ficção (FROMM 2011) cujo objetivo é promover o conhecimento acerca da compilação, processamento computacional de corpora e construção de terminologias para o ensino e a pesquisa em Tradução.

Apesar da especificidade de cada projeto, o objetivo em comum é verificar as ocorrências de termos, fraseologias, colocações, contextos definitórios e/ou explicativos e modalidades de tradução em legendas bilíngues para, posteriormente, descrevê-las e analisá-las de acordo com o objetivo de cada pesquisador. Ao término das pesquisas, parte dos dados coletados e processados via procedimentos metodológicos da Linguística de Corpus pode ser inserida no banco de dados terminográficos VoTec - Vocabulário Técnico Online (Fromm 2007) - cuja página e acesso encontram-se disponíveis na internet. ${ }^{2}$

Pretendendo a continuidade aos estudos nesta vertente, os objetos de análise foram as legendas do seriado Law and Order, uma espécie de seriadomatriz que possui várias spinoffs ou séries derivadas que contêm amostragem de linguagem policial e jurídica. Com base no estudo de Da Costa (2012) sobre

\footnotetext{
${ }^{1}$ Linha de pesquisa em Teoria e Análise Linguísticas do Programa de Pós-Graduação em Estudos Linguísticos da Universidade Federal de Uberlândia.

${ }^{2}$ www.ic.voteconline.com.br
} 
MURAD, C. R. R. O - O léxico da série Law and Order: uma análise inicial baseada em corpus paralelo

o emprego de terminologia por policiais civis, partimos da hipótese de que, em contexto especializado jurídico-policial, certas unidades da linguagem podem receber o estatuto de termos, sendo o contexto um dos principais fatores responsáveis pela transformação de determinados termos em outros, já que o intuito do uso é atender às peculiaridades profissionais de uma certa área que, neste caso, é uma área híbrida de especialidade: a jurídico-policial.

Nesse sentido, os objetivos gerais deste trabalho foram colocar em prática os conhecimentos teórico-metodológicos advindos da Linguística de Corpus para compilação e análise de corpora e fomentar a relação entre Tradução, Terminologia, Terminografia e Linguística de Corpus por meio da análise contrastiva do léxico em corpus paralelo inglês-português.

Os objetivos específicos perfizeram o seguinte rol de ações: i) estabelecimento de um corpus de estudo paralelo, constituído de legendas em inglês e em português; ii) utilização de corpora de referência em inglês e português para compor listas de palavras-chave para o levantamento dos candidatos a termo; iii) identificação e análise de alguns termos-chave relacionados ao campo semântico jurídico-policial a partir das ferramentas computacionais Wordlist, Keywords e Concord disponíveis no programa Wordsmith Tools 5.0 (SCOTT 2010) e sua tradução para o português.

\section{Revisão da Literatura: Terminologia, Corpora, Tradução e Legendagem}

Os corpora paralelos que contêm linguagem especializada podem revelar ricas fontes para o trabalho com levantamento de termos, colocações ou mesmo equivalências e correspondências interlinguais. A confluência entre as áreas de Terminologia, Linguística de Corpus e Tradução tem se mostrado de relevância na Linguística Descritiva e, mais especificamente, na sub-área de Terminografia 
MURAD, C. R. R. O - O léxico da série Law and Order: uma análise inicial baseada em corpus paralelo

com foco na elaboração de vocabulários. Vários estudiosos que lidam com textos de diversas especialidades, diversos desenhos de pesquisa e diferentes tipos de corpora, tais como paralelos, comparáveis, bilíngues ou multilíngues, têm feito trabalhos considerados fontes de referência para tradutores, professores e estudantes de línguas.

Em pesquisa ao site de dissertações e teses da Capes $^{3}$ pelas palavraschave 'tradução e terminologia', alguns trabalhos com textos jurídicos foram identificados. Laranjinha (1999) elaborou um glossário de colocações verbais do Direito Comercial, Ventura (2007) analisou termos de Contratos Internacionais em inglês e suas traduções para o português, Nobile (2008) comparou o tratamento dado ao termo Law por dois dicionários jurídicos bilíngues, SILVA (2008) observou a tradução do termo evidence em várias bases legais bilíngues e Orenha (2009) utilizou traduções juramentadas e não juramentadas para extrair colocações especializadas e colocações especializadas estendidas.

Apesar da reconhecida validade destas pesquisas que têm privilegiado textos-fontes pertencentes aos gêneros escritos tais como contratos, documentos e leis, esses não são os únicos a conterem termos de especialidade jurídica. É interessante notar, por exemplo, que no Corpus of Contemporary American English, ou COCA, o termo jurídico statutory rape ${ }^{4}$, aparece menos em textos do corpus acadêmico ${ }^{5}$ (20) do que em textos do corpus falado ${ }^{6}$ (121 ocorrências), um indício de que o termo tem sofrido um processo de vocabularização em inglês:

\footnotetext{
${ }^{3}$ Pesquisa feita em 14 de janeiro de 2013.

${ }^{4}$ estupro de menor, segundo dicionário online da Porto Editora.

${ }^{5}$ Subcorpora com 91 milhões de palavras, contendo artigos acadêmico-científicos de mais de 100 revistas.

${ }^{6}$ Subcorpora com 95 milhões de palavras, sendo a maior parte constituída por transcrições de diálogos em mais de 150 estações de rádio norte-americanas.
} 
MURAD, C. R. R. O - O léxico da série Law and Order: uma análise inicial baseada em corpus paralelo

\begin{tabular}{|c|c|c|c|c|c|c|}
\hline SECTION & ALL & SPOKEN & FICTION & MAGAZINE & NEWSPAPER & ACADEMIC \\
\hline FREQ & 199 & 121 & 11 & 12 & 35 & 20 \\
\hline PER MIL & 0.43 & 1.27 & 0.12 & 0.13 & 0.38 & 0.22 \\
\hline & & & & & & \\
$\begin{array}{c}\text { SEE ALL } \\
\text { SU-SECTIONS } \\
\text { AT ONCE }\end{array}$ & & & & & & \\
\cline { 2 - 7 } & & & & & & \\
\hline
\end{tabular}

Figura 1: Statutory rape no COCA

Semelhante constatação fez Da Costa (2012) na língua portuguesa. A pesquisadora descreve o vernáculo dos policiais civis do Rio Grande do Sul ao se referirem aos criminosos/infratores e aponta para o fato de que, por fazerem parte do grupo de profissionais cuja atividade fim é o uso da terminologia jurídica em contexto policial, contribuem para o surgimento de um vocabulário específico híbrido, jurídico-policial que, inclusive, não se encontra registrado em dicionários.

O direcionamento para o trabalho com a Terminologia e a Ficção via Linguística de Corpus proposto por Fromm (2011) parte de dois pressupostos teóricos. O primeiro, em conformidade com a proposta de Barbosa (2001) de estudo dos termos em contexto de uso, diz respeito ao fato de que, apesar dos vocábulos configurarem elementos padrões característicos de áreas de especialidade, eles “já há algum tempo, saíram das áreas de especialidade para frequentarem o falar cotidiano de grandes parcelas da população" (FROMM 2011: 2). O segundo aproxima-se da percepção de que os seriados acabam por emprestar a terminologia usada em várias áreas específicas de conhecimento, ou seja, apesar de vinculados à ficção, os termos acabam por conferir um status de realidade a alguns tipos de programa, inclusive aos seriados policiais, podendo configurar como corpora de exploração do vernáculo jurídico-policial em inglês/português.

A partir de resultados advindos do projeto Terminologia e Ficção, Fromm (2011: 2) identificou três padrões de uso de terminologia nos seriados que também podem ser usados como parâmetro de triagem dos mesmos para 
MURAD, C. R. R. O - O léxico da série Law and Order: uma análise inicial baseada em corpus paralelo

pesquisas terminológicas, a saber: i) séries com terminologia totalmente ficcional como Supernatural (estudada por CARNEIRO 2011); ii) séries que misturam ficção e ciência como Farscape (SILVA 2011) e Jornada nas Estrelas (Реіхото 2013) e iii) séries que retratam o cotidiano de médicos, investigadores, cientistas forenses tais como House (BANG 2011) e CSI (LAGO 2011).

O presente projeto inseriu-se no terceiro caso, pois Law and Order é uma série que retrata o cotidiano de investigadores, policiais, advogados, juízes e promotores, personagens inspirados em profissionais do ramo judicial-policial, dada a autenticidade da linguagem usada pelos personagens do seriado Law and Order, tornando a ficção mais próxima da realidade. Porém, neste corpus de estudo em específico, ressaltamos que não há somente especificidades jurídicas formais, tais como são retratadas em fontes terminológicas formais e dicionarizadas, pois os profissionais escolhem usar termos com base no empirismo.

Ainda sobre tradução e terminologia, convém salientar a importância de se inventariar termos e examinar suas equivalências lexicais, já que é possível fazer esse tipo de exame em corpus paralelo. É preciso deixar claro que os sistemas jurídicos (Civil e Common Law) são distintos e que a provável inexistência de equivalentes interlinguais perfeitos entre o inglês e o português não impedem o exercício de se investigar se os tradutores de termos da área de especialidade jurídico-policial em inglês investigada utilizam correspondentes específicos na língua portuguesa. A seguir, faremos breves considerações começando pela discussão acerca de alguns conceitos de legenda.

Segundo o dicionário Houaiss eletrônico, a legenda é um letreiro sobreposto à imagem de filmes, geralmente estrangeiros, que fornece a tradução da fala dos personagens. Essa informação deixa subentendido que as legendas, em geral, são textos traduzidos que tendem à oralidade.

No entanto, há dois tipos de legendas que geram diferentes conceituações. Existem as legendas ocultas ou fechadas, provenientes do sistema closed caption e as legendas traduzidas, resultantes do processo de 
MURAD, C. R. R. $O$ - O léxico da série Law and Order: uma análise inicial baseada em corpus paralelo

legendagem de uma língua para outra. Sobre as legendas ocultas, Mello (2005: 9) explica:

As legendas fechadas, além da tradução do texto oral, apresentam os ruídos, os sons emitidos pelas pessoas (ronco, suspiros, interjeições etc), a trilha sonora, transcritos de forma que os deficientes auditivos e portadores de deficiência leve possam desfrutar dos programas e filmes mais integralmente.

Trata-se das legendas com audiodescrição. Ainda sobre este tipo de legenda, existem dois métodos de inserção: o método síncrono e o método assíncrono. No primeiro, a inserção se dá via estenótipo. Há necessidade de um digitador ou de um reconhecedor de voz, os quais inserem as falas em programas de televisão transmitidos ao vivo. No método assíncrono, a inserção é offline, ou seja, é possível inserir o sinal das legendas diretamente na mídia e acioná-las toda vez em que o programa é reproduzido. É comumente utilizado em programas gravados e DVDs.

Neste trabalho, as legendas originais em inglês são as legendas originárias deste último método, o assíncrono, elaboradas para a audiência norte-americana e disponíveis para download pela internet. Elas contêm indicações de Narrator, mudanças de tom ("sofly”), interjeições ("oh”) e fillers (“er”, “uh”, “okay”) e alguns nomes próprios sem maiúsculas.

Sobre a tradução de legendas, há distinção entre as que são traduzidas por profissionais, denominadas de comerciais, e as que são traduzidas por fãs, denominadas de "piratas" (FEITOSA 2009: 18).

A tradução das legendas oficiais ou comerciais de Law and Order que são veiculadas na TV por assinatura, por exemplo, é feita por tradutores profissionais que trabalham em agências de tradução. As legendas são preparadas de tal forma que as mesmas são “queimadas", isto é, são imediatamente descartadas após uso, segundo informação dada pela equipe do 
MURAD, C. R. R. O - O léxico da série Law and Order: uma análise inicial baseada em corpus paralelo

Universal Channel. ${ }^{7}$ Outra característica do processo de legendagem na TV por assinatura é que, ao final da transmissão de cada episódio, aparece o nome da agência e o(a) tradutor(a) que realizou a tradução. As sinopses acessadas pelo controle remoto trazem informações gerais sobre a série seguida do número e do título de cada episódio que permanece em inglês.

A tradução das legendas descarregadas pela internet é geralmente feita por fãs. Feitosa as denominou de "piratas", ou ainda fansubs, fantitles ou "legendas de fãs para fãs", ao distingui-las das legendas comerciais (FEITOSA 2009: 13). Os sites www.opensubtitles.org e www.tvsubtitles.net funcionam como repositórios de legendas em diversas línguas. Contudo, disponibilizam um número maior de legendas originais do que traduzidas. 0 site www.legendas.tv disponibiliza as legendas originais em inglês e as legendas traduzidas em português e algumas outras línguas como o espanhol e o francês, de forma mais balanceada, isto é, o número de legendas em inglês corresponde ao número de legendas em português. Nem sempre disponibilizam o título do episódio. Quando o fazem, esses títulos permanecem em língua inglesa, sem tradução. Uma característica interessante é que os tradutores incluem notas culturais na página em que se solicita o download das legendas. Caso um usuário desse tipo de legenda queira, há possibilidade de contatar os tradutores por meio de um fórum de discussão permanente online ${ }^{8}$.

As legendas piratas são confeccionadas por equipes de fãs tradutores que se intitulam de "legenders". Existem várias, mais de 40, que se subdividem entre as séries e tipos de filmes que desejam traduzir. Em conversas pelo fórum, pudemos notar que há uma tendência de fidelização da equipe com o tipo de série ou filme que se está traduzindo.

\footnotetext{
7 Segundo o canal e a agência contratada para traduzir o seriado, devido à licença exclusiva de uso de direitos autorais pelo canal transmissor, o acesso às legendas em forma de texto não está disponível para compra.

8 www.onetrueforum.net, para acessar a equipe tradutora de Law and Order, e http: / / forum.legendas.tv/ para acessar o site de legendas.
} 
MURAD, C. R. R. O - O léxico da série Law and Order: uma análise inicial baseada em corpus paralelo

Em relação à padronização da legenda pirata em tela, há uma tendência atual em regrar alguns quesitos como o número de caracteres por linha. Antes era de 39, 40 e, no momento de confecção deste trabalho, circulava a proposta de alteração para 35. 0 padrão encontrado por Feitosa (2009: 84) em legendas comerciais dos dez filmes de terror que pesquisou foi de 32 caracteres, um pouco menor que as piratas, que podem chegar a 40 caracteres.

Os fãs tradutores se orgulham de estarem adiantados em relação ao lançamento de episódios por canais pagos ou DVDs. Buscam estar sempre em sincronia com os lançamentos das legendas em inglês na internet. Além disso, acreditam que elaboram legendas superiores às legendas oficiais no quesito fidelidade estilística à fala das personagens.

Embora a definição do dicionário induza o leitor a interpretar que legendas trazem traços de oralidade, proponho o entendimento de que, em geral, as legendas originais trazem mais características da língua falada do que as legendas traduzidas, independentemente da língua de origem. Trata-se de um gênero híbrido, com predomínio da oralidade.

Já as legendas comerciais traduzidas, conforme entendimento proposto tanto por Carvalho (2008) quanto por Silveira (2005), tendem a pertencer ao gênero escrito por estarem os tradutores condicionados a determinadas normas, tais como o corte de palavrões e xingamentos e a preferência do público pelo linguajar culto na tela, o que pode tolher a produção de uma variante com características exclusivas da oralidade (ALFARO 2005).

As legendas gratuitas são diferentes porque não apresentam um padrão. Visam apresentar com maior fidelidade as falas dos personagens e o conteúdo do seriado. Por buscarem essa diferenciação, acabam mantendo algumas características da fala original, como por exemplo, coloquialismos ("cara"), formas verbais de infinitivo terminadas em -ar e -er, como falar, prender, acentuadas, "falá", "prendê", "protegê", "acusá” e presença de palavrões e xingamentos ("filho da mãe", "diabos" e "vadia”).

A escolha pelo trabalho com as legendas piratas justifica-se por três motivos: primeiro, porque não foi possível adquirir as legendas comerciais 
MURAD, C. R. R. O - O léxico da série Law and Order: uma análise inicial baseada em corpus paralelo

transmitidas pelo canal pago em forma de texto. Segundo, porque as legendas gratuitas em inglês e em português existem em número correspondente, o que contribui para o balanceamento do corpus paralelo. E terceiro, seria interessante observar se os fãs tradutores adequam suas escolhas de acordo com o vernáculo jurídico-policial do português brasileiro ou se eles tendem a escolher termos consagrados e dicionarizados.

\section{Objeto de Estudo}

Law and Order é uma série ${ }^{9}$ do tipo dramática que tem feito sucesso na televisão norte-americana desde 1990. Em 1997, foi a vencedora de um prêmio baseado em audiência e, em seguida, passou a ser matriz de várias outras séries derivadas ou as chamadas spinoffs. O primeiro foi Law and Order: Special Victims Unit (SVU), que estreou em 1999 e, depois, Law and Order: Criminal Intent, em 2001. Law and Order: Trial by J ury durou somente uma temporada devido aos baixos índices de audiência. Law and Order: Los Angeles é última produção a franquia, estreando em 2010. Além das spinoffs, versões internacionais também foram realizadas. SVU e Criminal Intent também tiveram versões russas. A última adaptação foi britânica: Law and Order: UK, uma versão da série original Law and Order.

Desde a sua estreia em setembro de 1990, a série original totalizou vinte temporadas no ar nos Estados Unidos, com 452 episódios. No Brasil, algumas temporadas em versão dublada já foram transmitidas por alguns canais abertos e atualmente as temporadas legendadas tanto da matriz Law and Order de 1990 como de algumas de suas derivadas têm sido reprisadas via televisão por assinatura. ${ }^{10}$

\footnotetext{
9 Esta seção foi escrita com base na Wikipedia http://pt.wikipedia.org/wiki/Law_\%26_Order

10 Law and Order original e a derivada Special Victims Unit estavam sendo transmitidas pelo Universal Channel no momento desta pesquisa. A primeira temporada de Los Angeles também
} 
MURAD, C. R. R. O - O léxico da série Law and Order: uma análise inicial baseada em corpus paralelo

A matriz Law and Order é ambientada na cidade de Nova lorque e retrata a vida dos policiais (junior e senior detectives), policiais supervisores ou chefes (captains) que trabalham na Divisão de Homicídios, e promotores (district attorneys) que se subdividem em assistentes (assistant district attorneys e executive district attorneys) da Promotoria Pública de Manhattan (Manhattan District Attorney's Office). Alguns episódios são baseados em fatos reais, escândalos e acontecimentos com repercussão na mídia norte-americana em geral.

A derivada Law and Order Special Victims Unit é centrada em dois investigadores da Unidade de Vítimas Especiais, Olívia Benson e Elliot Stabler, que cuidam dos casos de abuso sexual envolvendo, na maioria das vezes, mulheres e menores. Trata-se de uma versão fictícia da Décima Sexta Delegacia de Polícia do Departamento de Polícia da Cidade de Nova York. Ao estilo do original Law \& Order, os temas dos episódios são retirados das manchetes ou baseados em histórias reais que receberam atenção da mídia. Os personagens de Law and Order Criminal Intent têm por objetivo desvendar os casos sob o ponto de vista do responsável pelo crime para, assim, compreender seus atos e levá-lo à justiça. O grupo de detetives denominado de Major Case Squad, ou Divisão de Casos Especiais, vai se deparar com casos protagonizados por assassinos especializados, como do tipo serial killers. Law and Order Trial by J ury tem como foco principal o julgamento dos acusados, mostrando também a preparação para tais julgamentos tanto do lado da acusação, como da defesa. Law and Order Los Angeles segue o mesmo formato do Law and Order original. A única diferença, além dos personagens, é que a série é ambientada na cidade de Los Angeles e segue a legislação do estado da Califórnia.

Apesar de conterem diferenças específicas, pode-se dizer que o objetivo em comum da série original e das derivadas é retratar o mundo do crime através dos pontos de vista de dois tipos de profissionais: os investigadores e os

havia sido transmitida pelo referido canal. Criminal Intent tem sido transmitida pelo canal pago AXN, do grupo Sony. Não encontramos registros sobre a transmissão de Trial by J ury no Brasil. 
MURAD, C. R. R. O - O léxico da série Law and Order: uma análise inicial baseada em corpus paralelo

promotores de justiça. Nos primeiros trinta minutos ${ }^{11}$, o foco recai sobre as investigações. Entram em cena os investigadores e os policiais cujo objetivo é apreender suspeitos para tentar constituir um caso. Há cenas de investigações nos locais dos crimes, peritos pesquisando impressões digitais, médicos legistas confeccionando laudos sobre as mortes, sendo que a presença maior é de policiais e delegados. Na segunda parte do episódio, o foco passa a ser no sistema judicial norte-americano e na ação dos promotores assistentes que, em equipe conjunta com os policiais investigadores, auxiliam a promotoria geral a processar os acusados.

Os episódios não possuem uma trama sequencial imediata como acontece nas telenovelas tipicamente brasileiras. Apesar de serem relativamente independentes um do outro, cada episódio possui começo, meio e fim, evidência de uma sequência cíclica que gira em torno de todo um processo que vai desde investigações e perseguições aos bandidos até a culminância do caso no tribunal.

O vocabulário evidenciado nas legendas no decorrer dos episódios e temporadas remete à ideia de um campo de linguagem específico. Os policiais, investigadores e funcionários que trabalham na delegacia utilizam termos, isto é, unidades lexicais próprias do grupo de profissionais ao qual pertencem, para se comunicarem entre si e com os promotores de justiça, advogados de defesa e juízes que, por sua vez, também utilizam termos próprios da área jurídica para se comunicarem nesse universo de discurso em que a linguagem policial e jurídica específica se interpenetram.

É possível acompanhar a série de vários modos: adquirindo um pacote de TV por assinatura que inclua os canais transmissores, comprando os DVDs das temporadas, alugando DVDs em locadoras ou ainda descarregando as temporadas ou episódios pela internet, sendo que o processo de legendagem e

${ }^{11}$ Se for considerado o tempo de intervalo comercial, caso contrário, seriam os primeiros vinte minutos corridos. 
MURAD, C. R. R. O - O léxico da série Law and Order: uma análise inicial baseada em corpus paralelo

as legendas em si variam caso a caso. Nesta pesquisa, como já foi mencionado, utilizamos as legendas disponíveis na internet para compilação dos corpora.

\section{Metodologia}

Existem várias tipologias de classificação de corpora. Para esta pesquisa, recorri ao esquema proposto por Teixeira (2008: 161) que se baseou em diversos autores para elaborar os seguintes critérios de classificação e descrição do corpora utilizado na pesquisa:

a) língua: bilíngue, par inglês-português;

b) data de publicação: sincrônico (período de tempo contínuo) e contemporâneo, pois a amostra de linguagem é representativa do inglês e do português atuais;

c) modo: escrito;

d) conteúdo: legendas em língua inglesa (transcrição das falas das personagens em formato closed caption) e portuguesa (traduções), contendo a variedade padrão das línguas inglesa e portuguesa, por ser escrito;

e) uso da pesquisa: dois subcorpora de estudo (em paralelo) e um corpus de referência, utilizado como termo de comparação;

f) autoria: escritores nativos, no caso do subcorpus de língua inglesa e tradutores nativos e de autoria coletiva no caso do subcorpus que usam o português na língua de chegada;

g) tamanho: corpus de estudo = médio-grande (de 1 a 10 milhões de palavras);

h) nível de codificação: não etiquetado; 
MURAD, C. R. R. O - O léxico da série Law and Order: uma análise inicial baseada em corpus paralelo

i) organização interna: corpus paralelo.

As estratégias de busca de subsídios externos (Alves, MagalHães, Pagano 2000: 39), isto é, textos paralelos, dicionários monolíngues e bilíngues, consultas a especialistas da área, internet como banco de informações para pesquisa em corpora de palavras serviram como critério para identificação de especialidade do termo e para análise do tratamento dado aos mesmos na tradução.

Além disso, foram utilizados o programa Wordsmith Tools versão 5.0 de Scott (2010) e três de suas principais ferramentas, conforme explicação de Berber Sardinha (1999):

a) Wordlist: possibilita confeccionar listas de frequência de palavras e analisar a densidade lexical dos corpora, como o número de tokens (total de palavras no texto), types (número do tipo de palavra que apareceu no corpus, sendo que diversos tokens da mesma palavra são contados como um único type) e a relação token-type, a qual designa a densidade lexical do texto ou a variedade lexical existente,

b) Keywords: possibilita a produção de listas de palavras-chave a partir das listas de frequência montadas pelo Wordlist, e

c) Concord: concordanciador que oportuniza o acesso ao contexto dos termos, às colocações e aos seus cotextos.

Foram preparados dois subcorpora para comporem o corpus paralelo: um com as legendas traduzidas para o português, que corresponderam exatamente a cada episódio de cada temporada e outro com as legendas originais em inglês. Foi priorizado o balanceamento dos corpora de legendas ao máximo e descartadas aquelas legendas sem suas respectivas correspondências. Pode-se perceber, pela tabela 1, que a maioria das legendas encontradas em pares foi 
MURAD, C. R. R. $O$ - O léxico da série Law and Order: uma análise inicial baseada em corpus paralelo

a das spinoffs Special Victims Unit e Los Angeles e não da série original Law and Order. Isso se deve ao fato de que o surgimento de sites de legendas em português aconteceu somente no século XXI, enquanto a série original data do século XX. Os “legendadores” piratas não se propuseram, neste caso, a traduzir as legendas de toda a série, mas só a partir dos capítulos que estavam no ar, quando começaram suas atividades.

No que se refere às legendas de Trial by J ury, que teve sua transmissão encerrada nos Estados Unidos, foram encontradas apenas cinco temporadas. Já as legendas de Criminal Intent têm circulação razoável. Na internet foram encontrados episódios esporádicos em português de cinco temporadas. A conclusão foi que, de modo geral, as legendas referentes à série original foram incluídas mais recentemente do que suas derivadas e nem sempre possuem a respectiva tradução. Por essas razões, foram utilizadas as seguintes legendas em que Temp. é temporada e Ep. é episódio:

Tabela 1. Legendas dos subcorpora de estudo

\begin{tabular}{|c|c|c|c|c|c|c|c|c|c|c|c|c|c|}
\hline \multicolumn{14}{|c|}{ Law and Order SPECIAL VICTIMS UNIT } \\
\hline Temp. & 1 & 2 & 3 & 4 & 5 & 7 & 8 & \multicolumn{2}{|c|}{9} & 11 & 12 & 13 & 14 \\
\hline Ep. & 22 & 21 & 23 & 25 & 25 & 22 & 22 & \multicolumn{2}{|c|}{$\begin{array}{l}1,3,4, \\
5,6,7, \\
9,11,16, \\
18,19\end{array}$} & 24 & 24 & 23 & 1 a 9 \\
\hline \multicolumn{14}{|c|}{ Law and Order CRIMINAL INTENT } \\
\hline Temp. & \multicolumn{3}{|l|}{1} & \multicolumn{3}{|l|}{2} & \multicolumn{2}{|l|}{7} & \multicolumn{3}{|l|}{9} & \multicolumn{2}{|l|}{10} \\
\hline Ep. & \multicolumn{3}{|c|}{$\begin{array}{l}1,2,9,15, \\
21\end{array}$} & \multicolumn{2}{|c|}{1 a 8} & & \multicolumn{2}{|c|}{1 a 14} & \multicolumn{3}{|c|}{1 a 9} & \multicolumn{2}{|l|}{1 a 8} \\
\hline \multicolumn{14}{|c|}{ Law and Order 1990 (MATRIZ) } \\
\hline Temp. & \multicolumn{5}{|l|}{1} & \multicolumn{4}{|c|}{2} & \multicolumn{4}{|c|}{20} \\
\hline Ep. & \multicolumn{5}{|c|}{ (completa) } & \multicolumn{4}{|c|}{ (completa) } & \multicolumn{3}{|c|}{4 a 17 e 20} & \\
\hline \multicolumn{14}{|c|}{ Law and Order LOS ANGELES } \\
\hline Temp. & \multicolumn{13}{|l|}{1} \\
\hline Ep. & \multicolumn{13}{|c|}{1 a 22 (completa) } \\
\hline \multicolumn{14}{|c|}{ Law and Order TRIAL BY JURY } \\
\hline Temp. & \multicolumn{13}{|l|}{1} \\
\hline Ep. & \multicolumn{13}{|c|}{1 a 5} \\
\hline
\end{tabular}


MURAD, C. R. R. O - O léxico da série Law and Order: uma análise inicial baseada em corpus paralelo

Apesar de sua existência, as legendas de Law and Order: UK não foram utilizadas por conterem a variação britânica. Vale lembrar que a variação do português analisada neste trabalho foi a do português brasileiro.

\section{Análises}

Neste artigo, farei algumas observações quanto à densidade lexical, chavicidade e frequência, interseção entre universos jurídico e policial, e ocorrência de equivalências relacionadas ao campo semântico Crimes.

\subsection{Densidade lexical}

Com base nas informações acessadas pela aba statistics, na ferramenta Wordlist, foi possível preencher a seguinte tabela:

Tabela 2. Informações numéricas sobre os corpora paralelos

\begin{tabular}{|l|c|c|}
\hline & Subcorpus em inglês & Subcorpus em português \\
\hline Seções (arquivos) & 396 & 396 \\
\hline Sentences & 349.482 & 336.868 \\
\hline Types & 34.816 & 49.274 \\
\hline Tokens (palavras no texto) & 5.456 .137 & 4.930 .288 \\
\hline Tokens used for Wordlist & 2.381 .245 & 2.063 .210 \\
\hline Relação token-type & 1,46 & 2,39 \\
\hline
\end{tabular}

Observa-se que, apesar do número igual de arquivos (396 sections em ambos), ou seja, do balanceamento do corpus paralelo, há algumas discrepâncias quanto ao número de frases (sentences), types e tokens.

A diferença entre o total de palavras do texto e o total de palavras usadas para a construção da wordlist se deve ao fato de que o número total de palavras 
MURAD, C. R. R. O - O léxico da série Law and Order: uma análise inicial baseada em corpus paralelo

inclui os horários indicativos de inserção das legendas. Para a construção da wordlist, no entanto, o programa elimina os números, diminuindo esse total.

Em relação ao número de frases, há mais em inglês (349.482) do que em português (336.868). Essa discrepância pode ter ocorrido em decorrência de dois fatores. 0 primeiro está relacionado com o fato de que as legendas em inglês são, em sua maioria, do tipo closed caption e contêm, devido às necessidades relacionadas à audiodescrição, mais itens linguísticos do que as legendas traduzidas que não são reproduzidas nas legendas feitas por fãs. Outro fator é que, em algumas legendas em português, a introdução feita pelo narrador havia sido excluída, o que também pode ter causado uma diminuição no número de frases que compõe os arquivos.

Em relação ao número de tokens, o número de palavras do corpus em inglês é maior do que o em português. Isso significa que houve uma diminuição do número de palavras traduzidas. Este fato pode ser um reflexo da diferença de objetivos das legendas, isto é, as legendas fechadas em inglês funcionaram como textos originais que foram alterados para se ajustarem ao objetivo da legendagem simples em português, sem audiodescrição.

Fromm e Silva (2011) explicam que a diminuição de palavras em corpus paralelo está ligada à frequência de utilização de modalidades de tradução afastadas da literalidade e mais próximas à omissão e à elipse, pois se a tradução tendesse à literalidade, estes números estariam mais próximos (Fromm, SILVA 2011: 11). Por outro lado, o uso da modalidade omissão pode estar relacionado a dois fatores, neste caso em específico, da tradução não oficial de legendas: às características do processo de legendagem, que ocasiona alterações em função de uma série de requisitos próprios do ofício de legendar e ao ajustamento adicional que teve que ser feito nas legendas fechadas que, ao serem utilizadas como textos de partida, foram submetidas a uma função diferente daquela em que foram originalmente idealizadas. Contudo, esse processo não ocasionou perda da variação lexical na tradução, pois o número de tipos de palavras em português, ou types, se deu em maior número do que no subcorpus em inglês. 
MURAD, C. R. R. O - O léxico da série Law and Order: uma análise inicial baseada em corpus paralelo

Confirmando esta análise, nota-se que a relação token-type é relativamente menor em inglês do que em português, isto é, o subcorpus em inglês possui menos types que as traduções. Como types representam o número de ocorrências únicas e tokens o número de todas as palavras, conclui-se que as legendas em inglês têm, de fato, uma densidade lexical menor que as legendas em português. Em outras palavras, o vocabulário das legendas em português pode ser considerado mais variado do que o das legendas utilizadas como textos de partida, sem os ajustes. É preciso ser considerado também que tenha havido uma simplificação do léxico da língua inglesa tendo em vista que o leitor das legendas em inglês apresenta algum grau de surdez e talvez tenha um domínio de língua inglesa diferente do falante nativo.

\subsection{Chavicidade e frequência}

Segundo Scott (2010), a chavicidade é uma qualidade que as palavras ou conjunto de palavras possuem e que pode ser medida a partir de textos. Uma palavra não pode ser chave em geral, em uma determinada língua. Ela só pode ser chave em um texto ou em um conjunto de textos em comparação com outros textos ou conjuntos de textos. Para sabermos sobre a chavicidade de uma palavra, começamos por medir a sua frequência de uso em determinado domínio. Após o levantamento das palavras-chave em cada subcorpus, foi feita a comparação entre ambas as listas em inglês e português com as respectivas listas de referência do American National Corpus (ANC) e do Banco do Português ${ }^{12}$, que resultou em listas de palavras-chave com 500 palavras em cada língua.

12 O American National Corpus (www.anc.org) é uma coleção eletrônica contendo textos com variação norte-americana a partir de 1990 para pesquisa linguística, educacional e lexicográfica de livre acesso, com 22 milhões de palavras em 2005. Para acessar o corpus: O Banco de Português é um corpus monitor do português do Brasil, atualizado constantemente. Em 2003, possuía 240 milhões de palavras (tokens). O Banco de Português foi criado e é mantido no âmbito do projeto DIRECT e faz parte dos Bancos de Dados do CEPRIL, LAEL, PUC/SP. Para maiores informações sobre o corpus, vide http://lael.pucsp.br/corpora/ 
MURAD, C. R. R. O - O léxico da série Law and Order: uma análise inicial baseada em corpus paralelo

Abaixo, as 20 primeiras ocorrências das listas:

\begin{tabular}{|c|c|c|c|c|c|c|c|c|c|c|c|}
\hline LA & & & . & vs & & LAW & ID OR & PT BR & EM PORTUGU & ÊS_Ist.kws & \\
\hline File & Edit & View & Compute & Settings & Window & File & Edit & View & Compute & Settings & Windows \\
\hline$N$ & & & Key word & Freq- & $\%$ (2C. I & $N$ & & & Key word & Freq- & $\%$ RC. F \\
\hline 1 & & & \# & 074,844 & 57.61 & 1 & & & & $866,02 d$ & 58.15 \\
\hline 2 & & & YOU & 67,097 & 1.26160 & $\mathrm{~N}$ & & & VOCÊ & 23,769 & $0.48193,1$ \\
\hline 3 & & & HER & 19,276 & $\begin{array}{lll}0.36 & 32\end{array}$ & 3 & & & EU & 22,899 & $0.46476, \varepsilon$ \\
\hline 4 & & & YOUR & 15,980 & $\begin{array}{lll}0.30 & 25\end{array}$ & 4 & & & ELA & 18,889 & $0.38341, \varepsilon$ \\
\hline 5 & & & HIM & 13,316 & $\begin{array}{lll}0.25 & 22\end{array}$ & 5 & & & ELE & 25,777 & $0.52776,1$ \\
\hline 6 & & & SHE & 17,643 & $0.33 \quad 34$ & 6 & & & ME & 11,801 & $0.24281, \varepsilon$ \\
\hline 7 & & & MR & 3,759 & $0.07 \quad 2$ & 7 & & & NÃO & 54,744 & $1.11,062, \varepsilon$ \\
\hline 8 & & & $\mathrm{ME}$ & 16,307 & 0.3135 & 8 & & & ESTAVA & 8,845 & $0.18190,1$ \\
\hline 9 & & & TIVE & 1,632 & 0.03 & 9 & & & ESTÁ & 15,837 & $0.32751,7$ \\
\hline 10 & & & STABLER & 1,105 & 0.02 & 10 & & & ISSO & 12,671 & $0.26542,7$ \\
\hline 11 & & & RAPE & 1,760 & 0.03 & 11 & & & DELA & 3,658 & $0.07 \quad 37, \S$ \\
\hline 12 & & & GONNA & 3,750 & $0.07 \quad 3$ & 12 & & & SIM & 5,438 & $0.11113, \epsilon$ \\
\hline 13 & & & RAPED & 1,235 & 0.02 & 13 & & & DELE & 4,184 & $0.08 \quad 63,2$ \\
\hline 14 & & & TELL & 4,574 & $0.09 \quad 5$ & 14 & & & & 1,546 & $0.03 \quad 2,1$ \\
\hline 15 & & & BENSON & 1,108 & 0.02 & 15 & & & LSSO & 1,019 & 0.02 \\
\hline 16 & & & HE'S & 6,015 & $\begin{array}{ll}0.11 & 10\end{array}$ & 16 & & & CARA & 2,992 & $0.06 \quad 31,4$ \\
\hline 17 & & & DETECTIVES & 968 & 0.02 & 17 & & & MEU & 6,286 & $0.13184, s$ \\
\hline 18 & & & MURDER & 1,900 & $0.04 \quad 1$ & 18 & & & SEI & 3,524 & $0.07 \quad 53,3$ \\
\hline 19 & & & GOT & 8,732 & $0.16 \quad 18$ & 19 & & & QUÊ & 2,376 & $0.05 \quad 17, \varsigma$ \\
\hline 20 & & & YOU'RE & 6,214 & 0.1211 & 20 & & & VOCÊS & 2,757 & $0.06 \quad 30,6$ \\
\hline
\end{tabular}

Figura 2. Recorte de 20 palavras-chave do subcorpus em inglês e português computadas pela ferramenta Keywords.

Nota-se uma incidência maior de pronomes na lista em português do que na lista em inglês, pois não foram utilizadas stoplists ${ }^{13}$ com palavras gramaticais, visto que nos corpora ainda estariam presentes os nomes dos personagens dos seriados. Em relação a esses últimos, os personagens, nota-se, pela frequência dos nomes Stabler, Benson, Elliot, que a maioria das legendas são, de fato, da derivada Special Victims Unit.

Há alta incidência das palavras utilizadas na introdução que é narrada no início de cada episódio da série: police, crime, attorneys, prosecute, offenders, heinous, detectives, squad, felonies e trial. Como quase todos os episódios incluídos contêm a introdução com tais palavras, provavelmente a frequente ocorrência das mesmas se deve a esse fato. Retiradas as palavras gramaticais e

${ }^{13}$ Listas com palavras que se deseja excluir da leitura feita pelo programa. 
188

MURAD, C. R. R. O - O léxico da série Law and Order: uma análise inicial baseada em corpus paralelo

os nomes de personagens, segue uma análise das vinte primeiras ocorrências em cada subcorpus:

Tabela 3. As vinte primeiras ocorrências não gramaticais nos subcorpora

\begin{tabular}{|c|c|c|c|c|c|c|c|}
\hline $\begin{array}{c}\text { Posiçã } \\
0\end{array}$ & Token & Freq. & $\begin{array}{c}\text { Keynes } \\
\mathrm{s}\end{array}$ & $\begin{array}{c}\text { Posiçã } \\
0\end{array}$ & Token & Freq. & $\begin{array}{c}\text { Keynes } \\
\text { s }\end{array}$ \\
\hline 1 & $\begin{array}{l}\text { Detectiv } \\
\mathrm{e}\end{array}$ & 1.632 & 4.419 & 1 & detetive & 1.546 & 10.343 \\
\hline 2 & Rape & 1.760 & 3.597 & 2 & cara & 2.992 & 9.721 \\
\hline 3 & Gonna & 3.750 & 3.580 & 3 & sei & 3.524 & 9.210 \\
\hline 4 & Raped & 1.235 & 3.355 & 4 & feira & 755 & 7.471 \\
\hline 5 & Tell & 4.574 & 3.264 & 5 & vamos & 3.721 & 7.460 \\
\hline 6 & $\begin{array}{l}\text { Detectiv } \\
\text { es }\end{array}$ & 968 & 2.826 & 6 & detetives & 923 & 7.003 \\
\hline 7 & murder & 1.900 & 2.825 & 7 & posso & 2.275 & 6.707 \\
\hline 8 & Got & 8.732 & 2.725 & 8 & certo & 3.386 & 6.585 \\
\hline 9 & honor & 1.367 & 2.351 & 9 & então & 6.069 & 6.333 \\
\hline 10 & victim & 1.156 & 1.889 & 10 & sabe & 3.616 & 6.113 \\
\hline 11 & Guy & 2.827 & 1.471 & 11 & estupro & 1.216 & 5.874 \\
\hline 12 & client & 1.056 & 1.465 & 12 & queria & 2.220 & 5.618 \\
\hline 13 & captain & 741 & 1.433 & 13 & vou & 2.721 & 5.346 \\
\hline 14 & Told & 3.214 & 1.431 & 14 & $\mathrm{Ei}$ & 1.034 & 5.268 \\
\hline 15 & Gotta & 832 & 1.306 & 15 & matou & 1.361 & 4.895 \\
\hline 16 & Sorry & 1.776 & 1.288 & 16 & sabia & 1.696 & 4.855 \\
\hline 17 & kid & 1.369 & 1.285 & 17 & bem & 7.288 & 4.831 \\
\hline 18 & arrest & 908 & 1.278 & 18 & garota & 1.161 & 4.821 \\
\hline 19 & witness & 878 & 1.275 & 19 & homicídio & 1.150 & 4.480 \\
\hline 20 & perp & 425 & 1.274 & 20 & viu & 1.677 & 4.458 \\
\hline
\end{tabular}


MURAD, C. R. R. O - O léxico da série Law and Order: uma análise inicial baseada em corpus paralelo

A tabela acima revela que em ambos os subcorpora a palavra detetive possui a maior frequência, não pela leitura da frequência, mas pela chavicidade. 0 número de Detective, detetive, detectives e detetives são as palavras-chave mais frequentes em seus respectivos corpora. No entanto, suas frequências e chavicidades (keyness) não foram as mesmas. Nota-se que a chavicidade em português foi bem maior do que em inglês, em ambos os casos. Depreende-se que as palavras não ocupam a mesma posição na lista porque o que determina a sua posição nela é a chavicidade, isto é, elas possuem a mesma keyness em relação aos respectivos corpora de referência utilizados para a computação das palavras-chave.

Em outras palavras, detective tem a mesma posição na lista decrescente de chavicidade em relação ao ANC assim como detetive tem em relação ao Banco do Português. Assim, conforme entendimento de Fromm e Silva (2011: 23), "em um corpus paralelo, duas palavras que possuem a mesma recorrência em um texto podem ter uma posição diferente na lista", por possuírem uma chavicidade diferente em relação ao corpus de referência de sua língua de origem.

Nesse sentido, em uma lista de palavras-chave, um token com alta frequência como sei (3.524), pode estar em uma posição inferior (no caso, posição 3) a uma palavra que possui bem menos frequência, como detetive (1.546, posição 1). Isso significa que, apesar de mais recorrente, sei possui menos chavicidade que detetive em relação ao corpus de referência.

É possível coincidir de uma palavra com baixa chavicidade também ter menor recorrência: guy está na posição 11 , ao passo que cara está na posição 2. Nesse caso, guy possui menos frequência e menos chavicidade. Entretanto, como já dito anteriormente, não se pode afirmar que sua baixa chavicidade se dê por sua baixa frequência no texto.

Portanto, em relação à tradução, não se deve examinar questões de fidelidade utilizando parâmetros como a frequência e a chavicidade. 0 que se pode fazer, no entanto, são considerações quanto à escolha de palavras. Nesse sentido, parece haver uma preferência em se usar o termo detetive, 
MURAD, C. R. R. O - O léxico da série Law and Order: uma análise inicial baseada em corpus paralelo

palavra-chave de maior chavicidade em ambos os corpora, tanto pelos tradutores profissionais, isto é, pelos responsáveis pela legendagem closed caption, quanto pelos amadores.

\subsection{Intersecção dos universos de discurso}

A análise contrastiva das palavras listadas anteriormente apontou para uma impossibilidade de separação dos universos examinados aqui, levando à adoção da expressão jurídico-policial para designar a conjunção destes dois contextos. Tem-se a maioria das ocorrências com honor com o pronome your compondo Your Honor na posição 22 da Wordlist, traduzido ora por meritíssimo (na posição 58 em português) e meritíssima (na 90), ora por excelência (344), e defendant (30), réu, palavras que caracterizam a formalidade da linguagem utilizada no tribunal.

A palavra perp (44), por exemplo, foi encontrada em alguns dicionários monolíngues online ${ }^{14}$. No UrbanDictionary, está como abreviação de perpetrator (criminoso, assassino, culpado) e no The Free Dictionary, ela é registrada como slang (gíria). Em português, tanto a palavra criminoso quanto assassino, figuram na lista de palavras-chave, sendo que aquela ocorreu na posição 63 e esta na 268. Foram essas as palavras mais usadas na tradução de perp, já que não aparece na lista de frequência a palavra bandido, por exemplo, um uso mais coloquial para perp. Além disso, houve uma tendência à informalidade em inglês nas linhas editadas pelo concordanciador que coocorrem com perp, como ausência de Do you na pergunta Think the perp meant do kill her on purpose? e de Are you em Taking a perp off the street? Ambos exemplos se encontram nas posições 2 e 5 das linhas de concordância (figura 3), respectivamente:

${ }^{14}$ www. urbandictionary.com/define.php?term=perp, www.thefreedictionary.com/perp> 
MURAD, C. R. R. O - O léxico da série Law and Order: uma análise inicial baseada em corpus paralelo

\begin{tabular}{|c|c|c|c|c|c|c|}
\hline \multicolumn{7}{|c|}{ Concord } \\
\hline File & Edit & View & Compute & Settings & Windows & Help \\
\hline N & \multicolumn{6}{|c|}{ Concordance } \\
\hline 1 & \multicolumn{6}{|c|}{$3500: 01: 44,558 \rightarrow 00: 01: 46,478$ Perp rammed her head into this mirror } \\
\hline 2 & \multirow{2}{*}{\multicolumn{6}{|c|}{$\begin{array}{r}00: 05: 30,109 \rightarrow 00: 05: 32,157 \text { Think the perp meant to kill her on purpose? } 105 \\
7000: 03: 31,168 \rightarrow 00: 03: 32,894 \text { Perp was smart. He copied the van. } 71\end{array}$}} \\
\hline 3 & & & & & & \\
\hline 4 & \multicolumn{6}{|c|}{ Well, it's pretty deserted. Easy for the perp to check in, $34800: 17: 13,788$-> } \\
\hline 5 & \multicolumn{6}{|c|}{$00: 19: 43,880 \rightarrow 00: 19: 45,636$ Taking a perp off the street? $43000: 19: 45,709$} \\
\hline 6 & \multirow{2}{*}{\multicolumn{6}{|c|}{$\begin{array}{l}: 03: 03,314 \rightarrow 00: 03: 05,740 \text { Okay. The perp grabbed his first victim } 5700: 03: 05 \text {, } \\
\text { zone. } 6500: 03: 27,856 \rightarrow 00: 03: 30,044 \text { Perp does the deed and only has to }\end{array}$}} \\
\hline 7 & & & & & & \\
\hline 8 & \multicolumn{6}{|c|}{$\rightarrow 00: 03: 34,769$ She'll do anything the perp wants because she wants to } \\
\hline 9 & \multirow{2}{*}{\multicolumn{6}{|c|}{$=01: 20,383 \rightarrow 00: 01: 22,742$ if he bit the perp while trying to protect her. $3300: 01$}} \\
\hline 10 & & & & & & \\
\hline
\end{tabular}

Figura 3. Linhas de concordância do termo perp.

\subsection{Ocorrências relacionadas ao campo semântico Crimes e suas equivalências}

O termo murder apareceu na posição 160, ocorrendo 1.905 vezes em 322 textos, enquanto que homicide está na posição 717, aparecendo 308 vezes em 158 textos, o que indica que há uma preferência pelo uso do termo murder no original. Na lista de 545 crimes do Código Penal de Nova lorque ${ }^{15}$, não aparecem os termos murder ou homicide. No entanto, aparecem os derivados do termo murder como murder in the first (second) degree, possibilitando a inferência de que estes dois últimos constituem termos específicos da área criminal norteamericana:

15 http: //ypdcrime.com/penallawlist.php 
MURAD, C. R. R. O - O léxico da série Law and Order: uma análise inicial baseada em corpus paralelo

Home | ABC Law | Criminal Procedure Law | Penal Law | Vehicle and Traffic Law | Web Site Map

\section{New York Penal Law}

The Penal Code column is being currently updated - adding hyperlinks to the section number. During this time the CODE column will NOT sort properly. Use the OFFENSE column to sort

Review New York Penal Law Crimes by Offense Level. Records listed on this page: 54

Return to Previous Page.

\begin{tabular}{|l|l|l|}
\hline PENAL LAW OFFENSE & CLASS \\
\hline Murder in the first degree & A-I Felony \\
\hline Murder in the seeendidegree & A-I Felony \\
\hline Non-support of a child in the first degree & E Felony \\
\hline Non-support of a child in the second degree & A Misdemeanor \\
\hline Obscenity in the first degree & D Felony \\
\hline Obscenity in the second degree & E Felony \\
\hline Obscenity in the third degree & A Misdemeanor \\
\hline Obstructing emergency medical services & A Misdemeanor \\
\hline Obstructing governmental administration by means of a self-defense spray device & 265.27 \\
\hline Obstructing governmental administration in the second degree & 235.07 \\
\hline Obstruction of governmental duties by means of a bomb destructive device explosive or hazardous substance & 235.06 \\
\hline Offensive exhibition & 235.05 \\
\hline
\end{tabular}

Figura 7. Excerto da lista com 545 crimes no Código Penal de Nova lorque

Em português, assassinato apareceu na posição 322, ocorrendo 742 vezes em 208 textos. Já homicídio apareceu na posição 207 da Wordlist, ocorrendo 1.150 vezes e em 265 textos, indicando, em português, uma frequência maior de uso do termo específico, como consta no Código Penal Brasileiro ${ }^{16}$.

Foi possível observar dois padrões relacionados às ocorrências com crimes: o padrão formal, mais relacionado à esfera jurídica, e o padrão informal de uso dos termos, sendo que o padrão informal pode estar relacionado à esfera policial, nos diálogos entre policiais e detetives. Por meio do botão Clusters, foram identificados os termos murder one correspondendo a murder in the first degree (sem equivalente perfeito, geralmente traduzido por homicídio qualificado) murder two para murder in the second degree (homicídio doloso, na maioria das vezes). O mesmo fenômeno ocorreu com rape: statutory rape (correspondente a estupro de vulnerável ${ }^{17}$ ), o padrão formal, e stat rape, o padrão informal, sem um correspondente dicionarizado

\footnotetext{
${ }^{16}$ www.planalto.gov.br/ccivil_03/decreto-lei/Del2848.htm

17 Termo definido em: www.direitonet.com.br/dicionario/exibir/1090/Estupro-de-vulneravel.
} 
MURAD, C. R. R. O - O léxico da série Law and Order: uma análise inicial baseada em corpus paralelo

em português. Ainda com rape, foram encontradas ocorrências informais como rape one, rape two que são, respectivamente, correspondentes a rape in the first degree e rape in the second degree, sem correspondentes dicionarizados em português. Assim ocorreu, sucessivamente, com os outros termos relacionados a Crime como em manslaughter one e two (correspondentes ao termo homicídio culposo) que foi usado informalmente como "man one, two". Todos estes termos apareceram na lista de 545 termos relacionados a crimes citada anteriormente. No entanto, resta detectar se a maioria de suas equivalências ou correspondências foi traduzida adequadamente em um futuro trabalho desta natureza.

Por ora, o máximo que se pode dizer é que a análise contrastiva das listas traz indício de literalidade na tradução como "homicídio em primeiro e segundo graus", "estupro em primeiro e segundo graus", e ainda "homicídio-suicídio" (homicídio seguido de suicídio) e "kit de estupro" (exame de corpo de delito), por falta de termos intercambiáveis em português. A graduação do crime, que está relacionada à intensidade da pena e não ao tipo do crime de acordo com a legislação norte-americana, é estabelecida pelos estados e não pela unidade de federação, como no Brasil. Portanto, é natural que se escolha traduzir literalmente ou se use correspondentes culturais mais próximos da língua de chegada.

\section{Considerações Finais}

De acordo com a proposta de análise inicial deste trabalho mediante arcabouço teórico-metodológico da Linguística de Corpus, foi possível detectar a ocorrência de termos-chave de especialidade jurídico-policial tanto nas legendas de ficção em inglês quanto nas legendas em português, confirmando a hipótese de que haveria termos de especialidade nas legendas contextualizadas como pertencentes à esfera jurídico-policial. 
MURAD, C. R. R. O - O léxico da série Law and Order: uma análise inicial baseada em corpus paralelo

Nas legendas originais foram identificados dois padrões de ocorrência de termos, uma tendência de transformação da linguagem jurídica em uma linguagem própria utilizada pela polícia no seriado. Assim, foi encontrado um padrão formal, característico da escrita e termos específicos relacionados ao campo semântico Crimes, e o padrão informal, com características de oralidade, modificação parcial dos termos específicos e expressões idiomáticas derivadas a partir dos termos-chave. Assim, as legendas originais se configuraram como possibilidade de se constituírem corpora passíveis de descrição e análise linguísticas e podem gerar contribuição para composição ou alimentação de glossários ou vocabulários jurídico-policiais mono ou bilíngues.

Por meio da utilização da lista de palavras-chave dos corpora paralelos foi possível examinar as equivalências contrastivamente, o que gerou observações importantes a respeito da tradução dos termos. De modo geral, houve manutenção da especificidade em português, embora as legendas sejam bastante limitadas em termos de espaço. A preferência pela literalidade é uma norma do fã tradutor, mas o que ficou mais evidente neste trabalho é que o tradutor opta por usar correspondentes terminológicos dicionarizados ao invés de utilizar a variação vernacular.

Apesar de o corpus não fornecer exemplos definitórios diretos, conforme orientação de estudos do projeto de pesquisa "Terminologia e Ficção", foi possível catalogar ocorrências terminológicas como murder e rape e suas derivações fraseológicas (murder in the first (second) degree, rape, rape (tool) kit, statutory rape), possibilitando a alimentação do Votec com definições totalmente baseadas em corpora.

Com o intuito de dar continuidade a este trabalho, poder-se-ia investigar a questão da Equivalência com maior rigor. A questão atual não é dar tratamento prescritivo à equivalência, estabelecendo parâmetros de correção do tipo “como a equivalência deve ser alcançada” em uma tradução, mas a que tipo de equivalência pode se chegar em determinados contextos (BAKER 1993: 234). Esta orientação de pesquisa se alinha com os Estudos Baseados em Corpora via instrumental metodológico da Linguística de Corpus os quais possibilitariam, 
MURAD, C. R. R. O - O léxico da série Law and Order: uma análise inicial baseada em corpus paralelo

neste caso da legendagem, verificar como tem sido feita a tradução de falsos cognatos, idiomatismos e fraseologias com o objetivo de se criar listas para o treinamento de tradutores e identificar quais equivalências terminológicas são possíveis neste contexto e quais não são, visando buscar traços de universais da tradução (TOURY 1980, BAKER 1993) de inglês para português em filmes e seriados legendados.

\section{Referências}

Alves, F. et al. Traduzir com autonomia: estratégias para o tradutor em formação. São Paulo: Contexto, 2000: 39-70.

BAKER, M. Corpus Linguistics and Translation Studies: Implications and Application. In: Baker, M.; Francis, G.; TogninI-Bonelli, E. (Eds.). Text and Technology: in Honour of John Sinclair. Amsterdam: John Benjamins, 1993: 233250.

BANG, M. Vocabulário de Especialidade na Ficção: análise do uso de termos da área médica na Série House M.D. Trabalho de Iniciação Científica, 2011. Universidade Federal de Uberlândia. Uberlândia, MG. 2011.

BARBoSA, M. A. Dicionário, vocabulário, glossário: concepções. In: Alves, I. M. (org.). A constituição da normalização terminológica no Brasil. São Paulo: FFLCH/CITRAT, 2001.

Berber-SARDINHA, A. Usando WordSmith Tools na investigação da linguagem. DIRECT Papers 40 ISSN 1413-442x. 1999. Disponível em: www2.lael.pucsp.br/direct/DirectPapers40.pdf. Acesso em: 26 abr. 2012. - Linguística de Corpus. São Paulo: Manole, 2004.

Biderman, M. T. C. Teoria linguística. São Paulo: Martins Fontes, 2001.

CARneiro, R. M. O. Linguística de Corpus e Ficção: uma análise contrastiva bilíngue do vocabulário de especialidade na série Supernatural. Trabalho de Iniciação Científica. Instituto de Letras e Estudos Linguísticos, Universidade Federal de Uberlândia, Uberlândia MG. 2012.

Carvalho, C. A. de. A tradução para legendas: dos polissistemas à singularidade do tradutor. Dissertação de Mestrado. 2005. 160 f. Departamento de Letras do Centro de Teologia e Ciências Humanas, Pontifícia Universidade Católica do Rio 
MURAD, C. R. R. O - O léxico da série Law and Order: uma análise inicial baseada em corpus paralelo

de Janeiro, Rio de Janeiro, RJ. 2005. 160 f. Disponível em: www.scribatraducoes.com.br/files/CarolinaAlfaroCarvalho_2005_TraducaoPar aLegendas_Dissertacao.pdf. Acesso em: 8 jan. 2010.

DA COSTA, Maria Izabel Plath. A terminologia empregada aos criminosos e/ou infratores pela polícia civil do Rio Grande do Sul. TradTerm, São Paulo,v.19, nov./2012, pp. 248-264.

FeitosA, M. P. Legendagem comercial e legendagem pirata: um estudo comparado. Tese de Doutorado. 2009. 162 f. Faculdade de Letras, Universidade Federal de Minas Gerais, Belo Horizonte, MG. 2009. 162 f. Disponível em: www.letras.ufmg.br/poslin/defesas/743D.pdf. Acesso em: 8 jan. 2010.

FerReira. M. C. O léxico dos relacionamentos amorosos da língua inglesa na sitcom Friends. 2008. 136 p. Dissertação de Mestrado. Universidade Federal de Uberlândia. Uberlândia, MG. 2008. 136 p.

Fromm, G. Ficção, Tradução, Terminografia e Linguística de Corpus: confluências. Anais do SILEL. Volume 2, no. 2. Uberlândia: EDUFU, 2011.

- VoTec: a construção de vocabulários eletrônicos para aprendizes de tradução. Tese de Doutorado em Estudos Linguísticos e Literários em Língua Inglesa. 2007. 215 f. Faculdade de Filosofia, Letras e Ciências Humanas, Universidade de São Paulo. 2007. 215 p.

Fromm, G.; Silva, F. O léxico maravilhoso de Alice. Revista Fronteira Digital. n. 4, 2011, pp.16-27.

LAGO, L. P. Análise de Vocabulário de Especialidade na Ficção na Série CSI: um estudo qualitativo de tradução. Trabalho de Iniciação Científica. 2011. Universidade Federal de Uberlândia. Uberlândia, MG. 2011.

LARANJINHA, A. L. T. Para um glossário bilingue - Português / Inglês de termos do direito comercial: colocações verbais. Dissertação de Mestrado. 1999. 129 f. Universidade de São Paulo, São Paulo, SP. 1999. pp. 129.

Mello, G. O tradutor de legendas como produtor de significados. Tese de Doutorado. 2005. 187 f. Instituto de Estudos da Linguagem. Universidade Estadual de Campinas. Campinas, SP. 2005. $187 \mathrm{fls.}$

NASCIMENTO, A. Linguística de Corpus e legendagem para surdos e ensurdecidos (LSE): uma análise baseada em corpus dos efeitos sonoros de filmes brasileiros em DVD. Anais do XI Encontro 2012. Disponível em: www.caravelas.icmc.usp.br/elc-ebralc2012/index.php/pt/elc2012anais/2uncategorised/76-103891. Acesso em: 10 mar. 2013.

NoBILE, M. G. C. Tradução e Lexicografia Jurídicas no Brasil - Análise de dois Dicionários Jurídicos Português-Inglês brasileiros, considerando as peculiaridades e os condicionantes culturais dos diferentes sistemas e 
MURAD, C. R. R. O - O léxico da série Law and Order: uma análise inicial baseada em corpus paralelo

linguagens jurídicas. Dissertação de Mestrado. 2008. 172 f. Universidade Federal de Santa Catarina. Florianópolis, SC. 2008. 1v. $172 \mathrm{f}$.

SILVA, F. S. Uma viagem ao corpus de Farscape: as questões de tradução envolvidas em um corpus trilíngue de ficção científica. Trabalho de Iniciação Científica 2012. Universidade Federal de Uberlândia. Uberlândia, MG. 2012.

SILVA, N. A. Análise da tradução do item lexical evidence para o português com base em um corpus jurídico. Dissertação de Mestrado em Estudos da Tradução. 2008. 118 f. Universidade Federal de Santa Catarina. 2008. 118 f.

ScotT, M. WordSmith Tools version 5. Liverpool: Lexical Analysis Software, 2010.

Keyness in texts. In: Studies in Corpus Linguistics. Bond, M.; SCOTT, M. (Eds). Amsterdam: John Benjamins, v. 41, 2010: 43-59.

TEIXEIRA, E. A Linguística de Corpus a serviço do tradutor: proposta de dicionário de Culinária voltado para a produção textual. 2008439 f. Faculdade de Filosofia, Letras e Ciências Humanas da Universidade de São Paulo. 2008. 439 f.

TOURY, G. In search of a theory of translation. Tel Aviv: The Porter Institute for Poetics and Semiotics, 1980.

VentuRa. L. H. P. Reflexões sobre terminologia jurídica bilíngue de contratos: subsídios para o tradutor de contratos em inglês. Dissertação de Mestrado. 2007. 124 f. Universidade Federal de Uberlândia. Uberlândia, MG. 2007. 124 f. 